\title{
Nociceptive reflexes and the somatic dysfunction: A model
}

\author{
RICHARD L. VAN BUSKIRK, DO
}

A model of somatic dysfunction is developed in which restriction in mobility and autonomic, visceral, and immunologic changes are produced by painrelated sensory neurons and their reflexes. Nociceptors are known to produce muscular guarding reactions, as well as autonomic activation, when musculoskeletal or visceral tissue is stressed or damaged. This guarding causes abnormal musculoskeletal position and range of motion. Local inflammatory responses and autonomic reflexes further reinforce nociceptor activity, maintaining restriction. Nociceptive autonomic reflexes also evoke changes in visceral and immunologic function. Finally, maintenance of muscles, joints, and related tissues in an abnormal guarding position causes changes in the connective tissues, solidifying the abnormal position. Stretching these tissues into a normal range of motion will restimulate the nociceptor, reflexly reinforcing the somatic dysfunction. This model has evolved from Korr's neurologic model but emphasizes the nociceptor and its reflexes as a source of the connective tissue, circulatory, visceral, and immunologic changes seen in the somatic dysfunction.

From the West Virginia School of Osteopathic Medicine, Lewisburg, WVa.

Reprint requests to Richard L. Van Buskirk, DO, medical director, Sarasota Walk-in Medical Center, 2000 Webber St, Sarasota, FL 34239.
The concept of the somatic dysfunction, originally termed the "osteopathic lesion," is a focal point in the practice and principles that distinguish osteopathic medicine. From the earliest formulations of Andrew Taylor Still, functional musculoskeletal restrictions have been known to include pain and autonomic arousal, and to be a source of visceral dysfunction and disease. ${ }^{1}$ The restriction in motion might be limited to a single joint, but more often includes changes in posture, limb use, and mobility that develop as compensation to the original restriction. Musculoskeletal tissue changes involve microscopic lesions, thickening of connective tissue and edema, ${ }^{2}$ rather than gross structural changes, such as muscle or ligament tears, tendon evulsions, overstretched connective tissue, or broken or abnormally shaped bones. However, such gross structural changes could eventuate in somatic dysfunction.

The musculoskeletal restrictions of the somatic dysfunction and the accompanying autonomic arousal, visceral dysfunction, and disease are generally related anatomically rather than diffusely, ${ }^{1-5}$ although the autonomic effect may be somewhat more widespread.$^{3-5}$ As noted by Still, ${ }^{1}$ this relationship is what is now termed "segmental," that is, following the pattern of innervation based on embryology.

A somatic dysfunction may originate in the musculoskeletal restriction, or it can be triggered by cutaneous, connective tissue, visceral, or central nervous system trauma or disease. ${ }^{1-5}$ It may involve structural and functional changes consistent with the effects of persistent autonomic drive, or the changes may be 
infectious. ${ }^{5}$ Because of the segmental specificity of the relations between the visceral and musculoskeletal components of the somatic dysfunction, musculoskeletal restrictions and superficial autonomic signs may be useful in di-

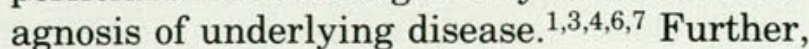
treatment of the musculoskeletal restriction removes causes or aggravating factors in visceral and systemic disease. ${ }^{1-3}$ By removing sources of physical limitation, irritation, and pain that potentially could evolve into disease, ${ }^{1-3,5,8}$ treatment of musculoskeletal restriction also promotes a general state of health, even when no obvious disease exists.

These ideas and inferences have distinguished osteopathic medicine since its founding by Still. Any model of the musculoskeletal changes of the somatic dysfunction must include these autonomic, visceral, and immunologic abnormalities or prove their association fallacious.

\section{Previous theories}

Most explanations of the somatic dysfunction propose one of three mechanisms as the initial and perpetrating factor, including changes in (1) circulation and extracellular fluid distribution; (2) connective tissues; or (3) neural mechanisms controlling muscles and the autonomic nervous system.

\section{Changes in flow of body fluids}

Beginning with Still's formulation, ${ }^{1}$ several models have focused on changes in the flow of body fluids as the cause of somatic dysfunctions. One such is Zink's model, ${ }^{9}$ which emphasizes the cascade effects imposed on both musculoskeletal and fascial mobility by failure of lymphatic and blood circulation. Zink proposes that such circulatory failures will restrict musculoskeletal movement and produce organ dysfunction by restricting necessary oxygen and nutrient access as well as toxin removal.

Somatic dysfunctions are accompanied by localized inflammation and edema due to alteration in blood and lymphatic circulation. ${ }^{2,3,5,10}$ Such changes can contribute to mechanical restriction in the affected tissues. Hypoxia sec- ondary to arterial restriction also has negative effects on function in musculoskeletal and other organ systems. Further, a restriction in venous or lymphatic flow at one location inevitably will back up fluid flow at more distal sites, contributing to a spreading locus of dysfunction. By reinstating adequate flow of body fluids, therapeutic remobilization of the musculoskeletal system should restore all affected tissues to normal.

Although it is clear that circulatory and lymphatic changes occur in somatic dysfunction, such changes cannot account for the segmental relationships between musculoskeletal restrictions and visceral dysfunction/disease fundamental to somatic dysfunctions. For instance, somatic dysfunctions at the level of T4 in the spine and its paraspinal muscles have been shown to exist as a common correlate of myocardial disease, ${ }^{7}$ yet no specific circulatory or lymphatic relationships exist between these two sites. Further, nothing in the circulatory model readily accounts for the close relationship between the restrictions of somatic dysfunction and autonomic arousal. Finally, if circulatory restrictions were to persist over long periods, they would produce ischemic and toxic tissue changes that should not be readily reversible, and certainly not reversible with the rapidity seen in many cases of manipulative treatment for somatic dysfunction. Thus, it is doubtful that circulatory changes are the cause of somatic dysfunctions, even though they are clearly a component of the response.

\section{Changes in connective tissues}

The second class of explanation for the somatic dysfunction focuses on changes in connective tissues. Early studies by Burns ${ }^{2}$ showed that somatic dysfunctions are accompanied by microscopic extravasation of blood, edema, and inflammation in the connective tissue of the affected joint and muscles. ${ }^{2,11}$ This extravasation resolves over time as these connective tissues thicken. ${ }^{2,11-14}$ Burns hypothesized that these biphasic changes in the connective tissues found throughout the body are responsible for restriction of mobility in joints and for the accompanying pain. 
Immobilization of connective tissue such as might occur after injury (splinting) does lead to changes in this tissue's organization. In normal connective tissue, the fibers - whether elastin or collagen-are oriented parallel to the forces ordinarily exerted through the tissue. ${ }^{15}$ When connective tissue is chronically shortened (as seen, for instance, in flexor tendons and intramuscular fascia with flexed immobilization of a limb), there is an increase in fibrocytes. These new cells produce additional fibers laid out in random matrix fashion, rather than along the original lines of force. ${ }^{13-15}$ The resulting tissue is resistant to restoration to its normal length and, at the same time, weaker along the original axis of strength. ${ }^{13-15}$ Immobilization of a muscle, even with the nerves intact, also leads to a decrease in muscle-fiber diameter and a fibrotic increase in connective-tissue mass. ${ }^{14-17}$ At the opposite end of the spectrum, connective tissue chronically stretched beyond its normal length will undergo creep, a process resulting in laxness if it is then returned to its normal length. ${ }^{15}$

Examination of a joint with somatic dysfunction reveals certain characteristics. First, the joint is displaced from its normal neutral position at rest (Fig 1A, C). Second, attempts to move the joint away from its aberrant rest position, toward and through its normal neutral position, reveals marked restriction in motion (Fig 1D). Finally, in moving the joint away from its normal neutral position, an unusually increased range of motion is often seen (Fig 1D). Whether the total range of motion is actually decreased is not clear, but as seen in Figure 1, the range of motion is at least displaced.

Given the foregoing characteristics, one muscle or group of muscles must be chronically shortened at rest (left "muscle" in Fig 1C), restricting movement in the direction opposite that of their normal action. Similarly, their antagonists (right "muscle" in Fig 1C) will be lengthened at rest compared with their normal state. Because both muscles are chronically held at an abnormal length, it would be expected that their connective tissues would be reorganized. The connective tissues of the chronically shortened muscle should assume a more random, shortened matrix. The connective tissues of the chronically elongated muscle should have undergone creep, producing unusual slackness. Similar reorganization will occur in joint capsules and other periarticular tissues. This reorganization will help maintain the abnormal range of motion.

It has been suggested that all connective tissue in the body is interconnected via subdermal and organ-level fascia. ${ }^{2,3,18}$ To the extent that this interconnection exists, through what amounts to another cascade effect, disease, trauma, or restriction at one locus in the connective tissue matrix of the body could affect the whole body. Certainly, such changes in connective tissue could help account for the spread of effects seen in the development of secondary somatic dysfunctions and somatic postural adjustments to somatic dysfunctions. However, as was the case with the circulatory models, a connective tissue model does not readily account for the segmental nature of the somatic dysfunction, nor for the related autonomic arousal and visceral effects.

\section{Neural mechanisms}

In the past 40 years, the work of Korr and Denslow has focused on a possible neural origin for the interrelated phenomena of the somatic dysfunction. Taking up Denslow's earlier findings, ${ }^{19,20}$ Korr has developed a widely accepted neural model concerning the origin and maintenance of the somatic dysfunction..$^{21-23}$

First, as Korr points out, of all possible mechanisms, only the nervous system operates over the short time course typical of the onset of the somatic dysfunction and its relief with manipulative treatment. ${ }^{23}$ Second, as demonstrated by Korr's researches, the somatic dysfunction always produces autonomic arousal, particularly in the sympathetic component of the autonomic nervous system..$^{5,24,25}$ This arousal is greatest in the parts of the body served by the same spinal cord segment as the musculoskeletal restriction, falling off in neighboring segments. ${ }^{23,24}$ Third, the musculoskeletal restrictions of a somatic dysfunction, are (continued on page 797) 


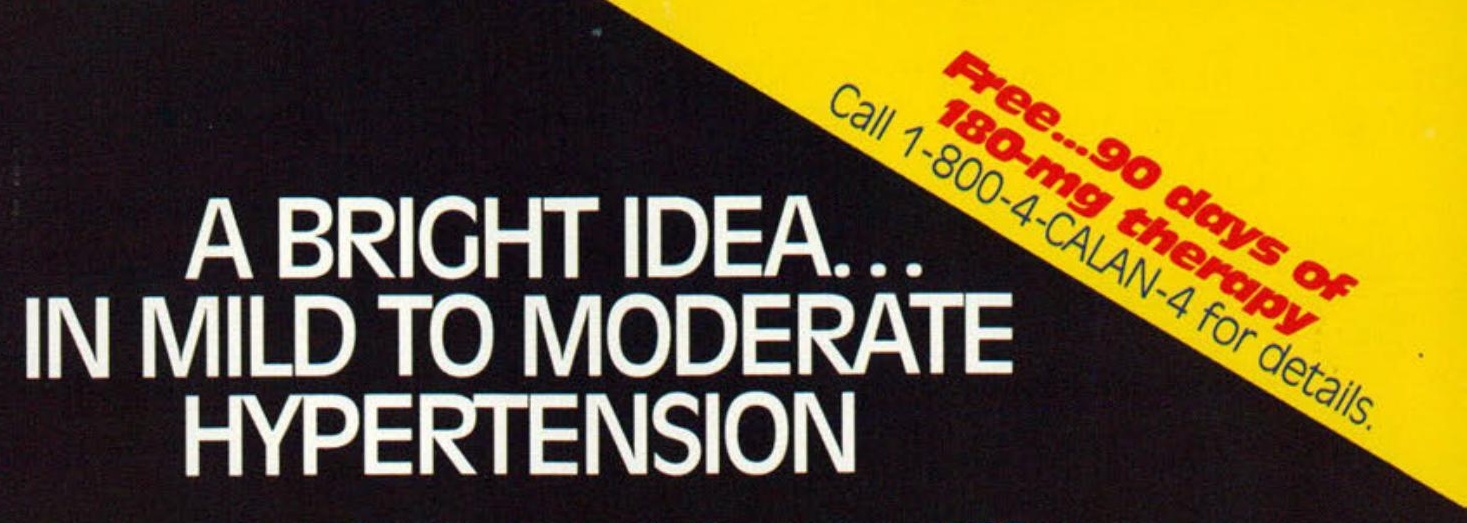

For once-a-day single-agent therapy...180 mg

-Efficacy proven comparable to $240 \mathrm{mg}^{1}$

-24-hour control with once-daily dosing ${ }^{1 \star}$

- Well-tolerated low-dose therapy

- An economical choice

"Total daily dosages above $240 \mathrm{mg}$ are administered in divided doses Calan SR should be administered with food tConstipation, the most commonly reported side effect of Calan $\mathrm{SR}$, is easily managed in most patients

Please see next page of this advertisement for references and a brief summary of the prescribing information.

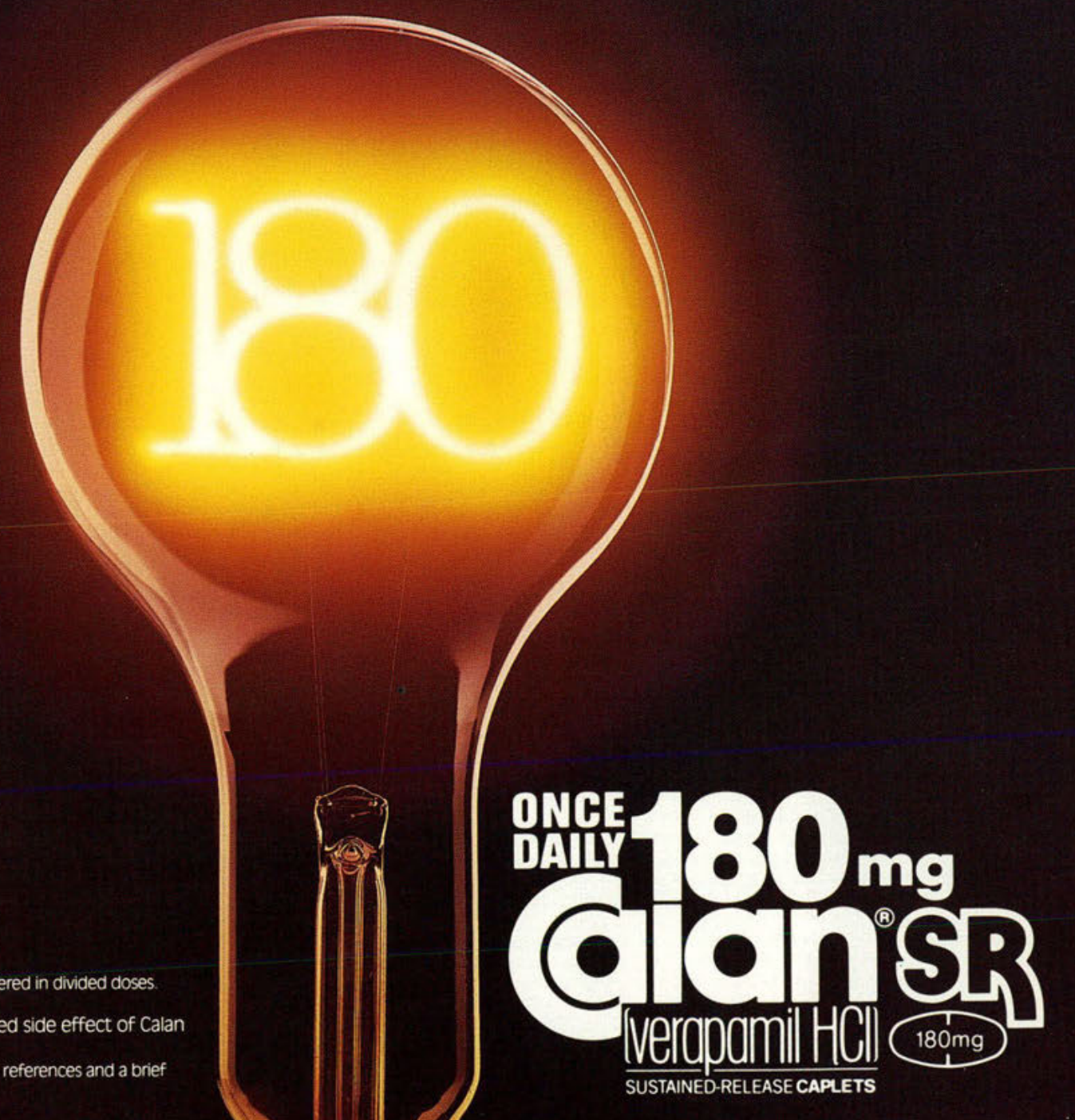




\section{The 1988 Joint National Committee on Detection, Evaluation, and Treatment of High Blood Pressure recommends that blood pressure be controlled "... with the fewest drugs at their lowest dose...."}

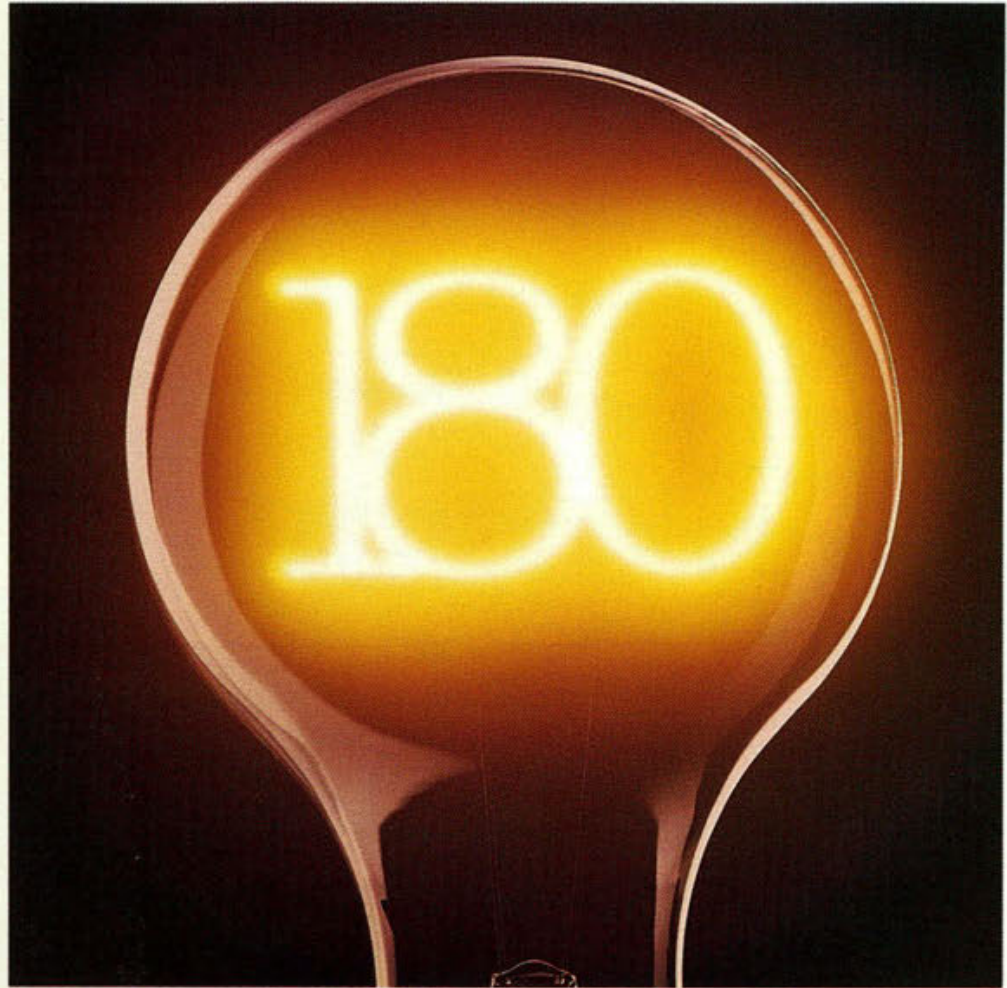

\section{When you want the single-agent safety and efficacy of lower dosage verapamil SR therapy...}

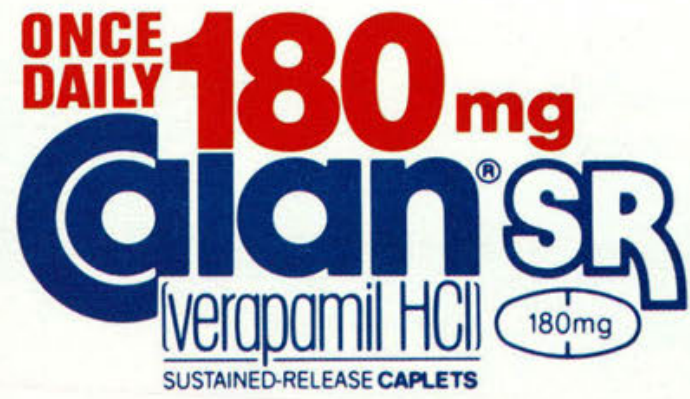

in verapamil SR therapy

\section{References:}

1. Data on file, G.D. Searle \& Co.

2. 1988 Joint National Committee: The 1988 report of the Joint

National Committee on Detection, Evaluation, and Treatment of High

\section{Blood Pressure. Arch Intern Med 1988;148:1023-1038}

\section{BRIEF SUMMARY}

Contraindications: Severe LV dysfunction (see Warnings), hypotension (systolic pressure $<90 \mathrm{~mm} \mathrm{Hg}$ ) or cardiogenic shock, sick sinus syndrome (if no pacemaker is present), 2nd- or 3rd-degree AV block (if no pacemaker is present), atrial flutter/fibrillation with an accessory bypass tract (eg, WPW or LGL syndromes), hypersensitivity to verapamil.

Warnings: Verapamil should be avoided in patients with severe LV dysfunction (eg, ejection fraction $<30 \%$ ) or moderate to severe symptoms of cardiac failure and in patients with any degree of ventricular dysfunction if they are receiving a beta-blocker. Control milder heart failure with optimum digitalization and/or diuretics before Calan SR is used. Verapamil may occasionally produce hypotension. Elevations of liver enzymes have been reported. Several cases have been demonstrated to be produced by verapamil. Periodic monitoring of liver function in patients on verapamil is prudent. Some patients with paroxysmal and/or chronic atrial flutter/fibrillation and an accessory AV pathway (eg. WPW or LGL syndromes) have developed an increased antegrade conduction across the accessory pathway bypassing the AV node, producing a very rapid ventricular response or ventricular fibrillation after receiving I.V. verapamil (or digitalis). Because of this risk, oral verapamil is contraindicated in such patients. AV block may occur (2nd- and 3 rd-degree, $0.8 \%$ ). Development of marked 1st-degree block or progression to 2 nd- or 3rddegree block requires reduction in dosage or, rarely, discontinuation and institution of appropriate therapy. Sinus bradycardia, 2nd-degree AV block, sinus arrest, pulmonary edema and/or severe hypotension were seen in some critically ill patients with hypertrophic cardiomyopathy who were treated with verapamil.

Precautions: Verapamil should be given cautiously to patients with impaired hepatic function (in severe dysfunction use about $30 \%$ of the normal dose) or impaired renal function, and patients should be monitored for abnormal prolongation of the PR interval or other signs of overdosage. Verapamil may decrease neuromuscular transmission in patients with Duchenne's muscular dystrophy and may prolong recovery from the neuromuscular blocking agent vecuronium. It may be necessary to decrease verapamil dosage in patients with attenuated neuromuscular transmission. Combined therapy with beta-adrenergic blockers and verapamil may result in additive negative effects on heart rate, atrioventricular conduction and/or cardiac contractility; there have been reports of excessive bradycardia and AV block, including complete heart block. The risks of such combined therapy may outweigh the benefits. The combination should be used only with caution and close monitoring. Decreased metoprolol clearance may occur with combined use. Chronic verapamil treatment can increase serum digoxin levels by $50 \%$ to $75 \%$ during the first week of therapy, which can result in digitalis toxicity. In patients with hepatic cirrhosis, verapamil may reduce total body clearance and extrarenal clearance of digitoxin. The digoxin dose should be reduced when verapamil is given, and the patient carefully monitored. Verapamil will usually have an additive effect in patients receiving blood-pressure-lowering agents. Disopyramide should not be given within 48 hours before or 24 hours after verapamil administration.

Concomitant use of flecainide and verapamil may have additive effects on myocardial contractility, AV conduction, and repolarization. Combined verapamil and quinidine therapy in patients with hypertrophic cardiomyopathy should be avoided, since significant hypotension may result. Concomitant use of lithium and verapamil may result in a lowering of serum lithium levels or increased sensitivity to lithium. Patients receiving both drugs must be monitored carefully. Verapamil may increase carbamazepine concentrations during combined use. Rifampin may reduce verapamil bioavailability. Phenobarbital may increase verapamil clearance. Verapamil may increase serum levels of cyclosporin. Concomitant use of inhalation anesthetics and calcium antagonists needs careful titration to avoid excessive cardiovascular depression. Verapamil may potentiate the activity of neuromuscular blocking agents (curare-like and depolarizing); dosage reduction may be required. Adequate animal carcinogenicity studies have not been performed. One study in rats did not suggest a tumorigenic potential, and verapamil was not mutagenic in the Ames test. Pregnancy Category C. There are no adequate and well-controlled studies in pregnant women. This drug should be used during pregnancy, labor, and delivery only if clearly needed. Verapamil is excreted in breast milk; therefore, nursing should be discontinued during verapamil use.

Adverse Reactions: Constipation (7.3\%), dizziness (3.3\%), nausea (2.7\%), hypotension (2.5\%), headache $(2.2 \%)$, edema $(1.9 \%)$, CHF, pulmonary edema $(1.8 \%)$, fatigue $(1.7 \%)$, dyspnea $(1.4 \%)$, bradycardia: $\operatorname{HR}<50 / \mathrm{min}(1.4 \%)$, AV block: total $1^{\circ}, 2^{\circ}, 3^{\circ}(1.2 \%), 2^{\circ}$ and $3^{\circ}(0.8 \%)$, rash $(1.2 \%)$, flushing $(0.6 \%$ ), elevated liver enzymes. The following reactions, reported in $1.0 \%$ or less of patients, occurred under conditions where a causal relationship is uncertain: angina pectoris, atrioventricular dissociation, chest pain, claudication, myocardial infarction, palpitations, purpura (vasculitis), syncope, diarrhea, dry mouth, gastrointestinal distress, gingival hyperplasia, ecchymosis or bruising, cerebrovascular accident, confusion, equilibrium disorders, insomnia, muscle cramps, paresthesia, psychotic symptoms, shakiness, somnolence, arthralgia and rash, exanthema, hair loss, hyperkeratosis, macules, sweating, urticaria, Stevens-Johnson syndrome, erythema multiforme, blurred vision, gynecomastia, increased urination, spotty menstruation, impotence.

\section{SEARLE $\begin{aligned} & \text { G.D. Searle \& Co. } \\ & \text { Box 5110, Chicago, IL.60680 }\end{aligned}$}

Address medical inquiries to:

G.D. Searle \& Co.

Medical and Scientific

Information Department

4901 Searle Parkway

Skokie, IL 60077 

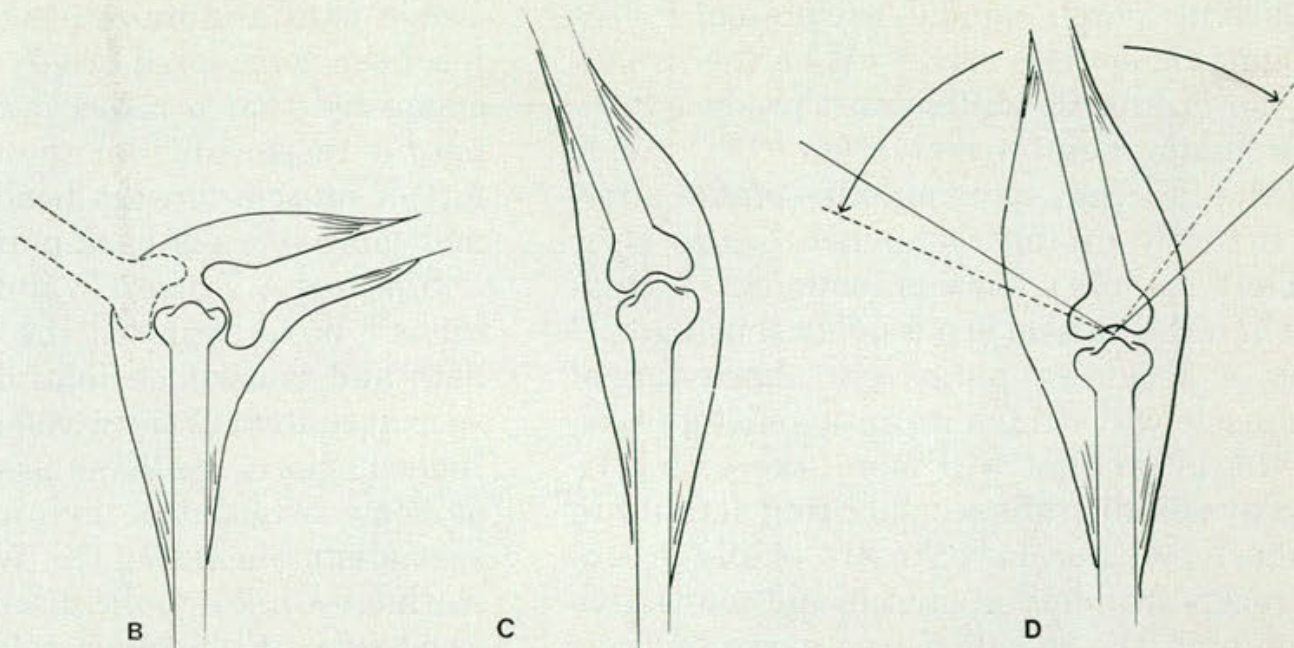

Figure 1. Relation between joint position and range of motion. A: Normal or neutral position. B: Normal range of motion. C: "Rest" position of a joint in somatic dysfunction is displaced from neutral. D: Range of motion in somatic dysfunction is also displaced, with loss of range toward the side away from the nonneutral rest position as compared with normal.

accompanied by an increased excitability in the motor neurons serving the affected (shortened) muscles. Denslow ${ }^{19,20}$ had shown hyperexcitability in paravertebral muscles innervated by nerves from a spinal segment in which the vertebra was misaligned. Korr and Denslow then showed that pressure on unaffected vertebrae had greater effects on paravertebral muscles of a lesioned segment than on their own paravertebral muscles, suggesting hyperirritability in the motor neurons of the lesioned segment. ${ }^{21}$ The implication was that the restrictions in motion seen in a somatic dysfunction are produced by the chronic shortening of muscles driven by hyperirritable motor neurons. Thus developed the idea that the spinal cord segment involved in a somatic dysfunction acted as a "neurologic lens," focusing activity on the affected spinal segment. ${ }^{22}$

Finally, Korr ${ }^{22,23}$ proposed that the motor neuron hyperexcitability in a somatic dysfunction was the result of afferent inputs to the cord, specifically from the muscle spindle proprioceptors of the affected muscles themselves. His criteria for such a decision were that the sensory receptors involved should be: (1) related to musculoskeletal activity; (2) ex- citatory to the affected motor neurons; and (3) capable of continuously firing when the muscle was shortened. ${ }^{23}$

The only receptors that appeared to fulfill these criteria were the muscle spindles. ${ }^{22,23}$ Korr's model suggested that when an actively contracting muscle was acutely shortened by an outside force, the spindle would be silenced. However, according to Korr, the nervous system requires continuous spindle activity from a muscle in order to operate the muscle. Therefore, the nervous system would increase gamma efferent activity to the spindle to turn it back on. This would produce a discrepancy between spindle drive and the already maximally shortened muscle. ${ }^{23}$ Any attempt to recover from this extreme situation would be resisted because the accidentally shortened muscle would continue to be reflexly maintained in its shortened position, particularly when stretched.

Although at the time Korr's proposal accurately reflected understanding of muscle-spindle function, over the years problems have developed with the muscle-spindle portion. Other receptors are known that could produce similar results, ${ }^{26}$ and somatic dysfunction can be triggered from tissues, such as visceral tissues, 
in which no muscle spindles are present. ${ }^{23}$ Further, muscle-spindle activity is neither necessary nor ordinarily sufficient to produce muscle or motor neuron activation. ${ }^{12,27-29}$ Aside from the fact that some muscle-spindle afferents actually inhibit motor neurons to their muscle, ${ }^{30}$ spindle silence is common, ${ }^{27}$ including when the muscle is passively shortened. ${ }^{29}$

Again, because rapid passive shortening of one muscle will stretch its antagonist muscle, it is the latter that will more likely be activated by spindle reflexes, blocking activity in the shortened muscle. ${ }^{31}$ Finally, of all the sensory receptors found in muscle and connective tissue, only the so-called free nerve endings appear to activate the sympathetic nervous system. ${ }^{32,33}$ Given that the muscle spindle acts differently than originally proposed by Korr and the fact that autonomic arousal is a major feature of somatic dysfunction, ${ }^{1-7,24,25}$ it is improbable that the muscle spindle plays a central role in generation or maintenance of a somatic dysfunction.

If the spindle afferent is not the principal player in the generation of the somatic dysfunction, are there other candidates that might fill the bill? One possibility, of course, is that the etiology may lie in an imbalance of a variety of sensory inputs to the central nervous system. ${ }^{34}$ Although such a "pattern" hypothesis is attractive in allowing for the variety of visceral and somatic interactions involved in somatic dysfunctions, it is very difficult to test. Further, if a single triggering agent could be identified accounting for most or all of the phenomena known to be subsumed in the somatic dysfunction, it would be, by virtue of its simplicity (Ocam's razor), more attractive, at least until it was disproved or other sources proved.

Is there then a single sensory element that might fill the bill as sole agent in initiating the somatic dysfunction? One possibility is pain, which almost universally accompanies somatic dysfunction. Pain may occur at the site of restriction or at a referred site. ${ }^{1-8,14,21-25}$ Given the connection between pain and somatic dysfunction it is worth investigating pain as a possible source rather than as a mere symptom or epiphenomenon. The relation be- tween pain and musculoskeletal restriction has been considered briefly by Ruch, ${ }^{35,36}$ who suggested that a reflex cycle of pain-spasmpain is responsible for the sustained discomfort of muscle tension headaches, torticollis, and some types of back pain. ${ }^{35,36}$

Similarly, Travell ${ }^{37}$ and Travell and Simons ${ }^{38}$ have explored the relation between pain and musculoskeletal dysfunction in the special context of the myofascial tender point. Indeed, sports medicine practitioners as well as some osteopathic manipulative medicine specialists (including Drs William Wyatt and Anthony Chila, public discussion) have often assigned pain a primary role in musculoskeletal dysfunction; however, few formal theories appear to have been proposed to date. One factor that has tended to diminish acceptance of such a causative relation is that somatic dysfunction, once developed, will persist even though the associated pain may be only intermittent. In spite of this problem, a solid case can be made for "pain" as the primary cause of somatic dysfunction.

\section{Pain and nociception: \\ Its reflexes and consequences}

Pain is a sensation stemming from events that are potentially or actually damaging to the tissue. ${ }^{39}$ Although pain can arise within the central nervous system without peripheral stimulus, ${ }^{36,40}$ in most cases it results from stimulation of particular peripheral receptors, the nociceptors. ${ }^{36,40-42}$ Use of strong mechanical force, certain chemicals, temperatures above $45^{\circ} \mathrm{C}$, or any other potentially damaging stimulus causes these nociceptors to generate signals (action potentials) that are carried to the spinal cord or brainstem. Often, this "signaling" stimulates pathways to higher centers strongly enough to allow us to perceive these events as pain.

However, not all signals in the peripheral nociceptors reach consciousness as pain. $36,40,41$ The central nervous system appears able to censor its nociceptor inputs both in the spinal cord and higher. ${ }^{40,41}$ This self-censorship involves, at least in part, the endogenous opiate systems and can cause considerable variabil- 
ity in pain thresholds and perceived pain intensity, even with the same stimulus in the same person. This self-censorship may also be the basis for the markedly elevated pain thresholds sometimes seen on the battlefield. ${ }^{40,41}$ In contrast, peripheral nociceptors show a more consistent response both between individuals and over time. ${ }^{40-42}$ To distinguish between peripheral stimuli that can produce pain and the experience of pain itself, we speak of the stimulus as noxious, the experience as pain, and reflexes directly stimulated by nociceptors as nocifensive ci-43 $^{4}$ or nociautonomic.

Nociceptors belong to the class of small myelinated (A $\delta$ or type III) and unmyelinated (C fiber, or type IV) peripheral neurons. ${ }^{40-42}$ They originate as sensory free nerve endings in all connective tissue of the body, with the exception of the stroma of the brain. ${ }^{36,40,44-47}$ Thus, these unencapsulated ramifying endings are found in the dermis, subdermis, joint capsules, ligaments, tendons, muscle fascia, periosteum, all blood vessel stroma except that of the capillaries, in the meninges, and in the stroma of all internal organs. There are variations in the numbers of these free nerve endings in various organs. Large numbers are seen in the der$\mathrm{mal} / \mathrm{subdermal} \mathrm{tissues,} \mathrm{periosteum,} \mathrm{perito-}$ neum, and connective tissues of the muscles. Gastrointestinal organ stroma show relatively few. ${ }^{36,40,44-47}$ However, pain and its related responses can be elicited from any organ innervated by free nerve endings.

Free nerve endings are predominantly responsive to noxious stimuli, although a few respond only to benign stimuli and some to both noxious and benign stimuli. ${ }^{40-42}$ All free nerve endings responsive to noxious stimuli contribute to noxious reflexes and the experience of pain should the stimulus be strong enough. $36,40-42,48$ The only variation noted in pain sensations is that some can be characterized as sharp, cutting, piercing, and relatively well localized, ${ }^{49}$ whereas others are experienced as dull, throbbing, and poorly localized. ${ }^{26,40,48,49}$ Although some attempt has been made to differentiate these sensations as coming from superficial and deep sources in the body, respectively, there appears to be little functional difference in their ability to generate reflex effects. ${ }^{36,40}$

Nociceptors typically have many peripheral branches that innervate adjacent areas of the same structure. ${ }^{41,44-47}$ However, the peripheral branches of some $\mathrm{A} \delta$ and $\mathrm{C}$-fiber neurons from upper thoracic dorsal root ganglia project branches to both the brachial plexus and the pericardium ${ }^{50,51}$ (Fig 2, right). Similar visceral-somatic joint innervation is expected to be a common event in the body.

When one branch of a nociceptor is stimulated, the action potential not only proceeds centrally toward the spinal cord, but also peripherally out the other branches of that neuron. At all peripheral and central terminals of the activated nociceptor, the action potential releases peptide neurotransmitters, including substance P and, possibly, somatostatin. ${ }^{40,41}$ These peptide neurotransmitters act peripherally as vasodilators and as chemical attractants for tissue macrophages and lympocytes. ${ }^{52}$ They also stimulate release of and act synergistically with inflammatory chemicals like histamine, serotonin, kinenogens, and complement activators. ${ }^{52}$ These latter chemicals also produce vasodilation and act as further stimulants for phagocytosis and inflammatory chemotaxis. ${ }^{11}$

Some inflammatory events can occur at the actual site of damage (the weal) without intervention by the nociceptor. However, the spread of inflammation to surrounding areas (flair) occurs only through the agency of nociceptors with branches in the actual site of damage $^{40}$ (Fig 2, left). Whether this "axon reflex" 40 operates between distant organs served by the same nociceptor is not known, but appears likely. The idea that damage at one site, like the left shoulder, could elicit flairtype responses in a distant organ served by the same nociceptors, such as the heart, is highly provocative (Fig 2, right).

Aside from causing inflammation, vasodilation and the resulting induration at the damage site, and other terminations of the activated nociceptor, the stew of chemicals released as a result of nociceptor action will decrease the threshold of nociceptors. ${ }^{36,40,41}$ 


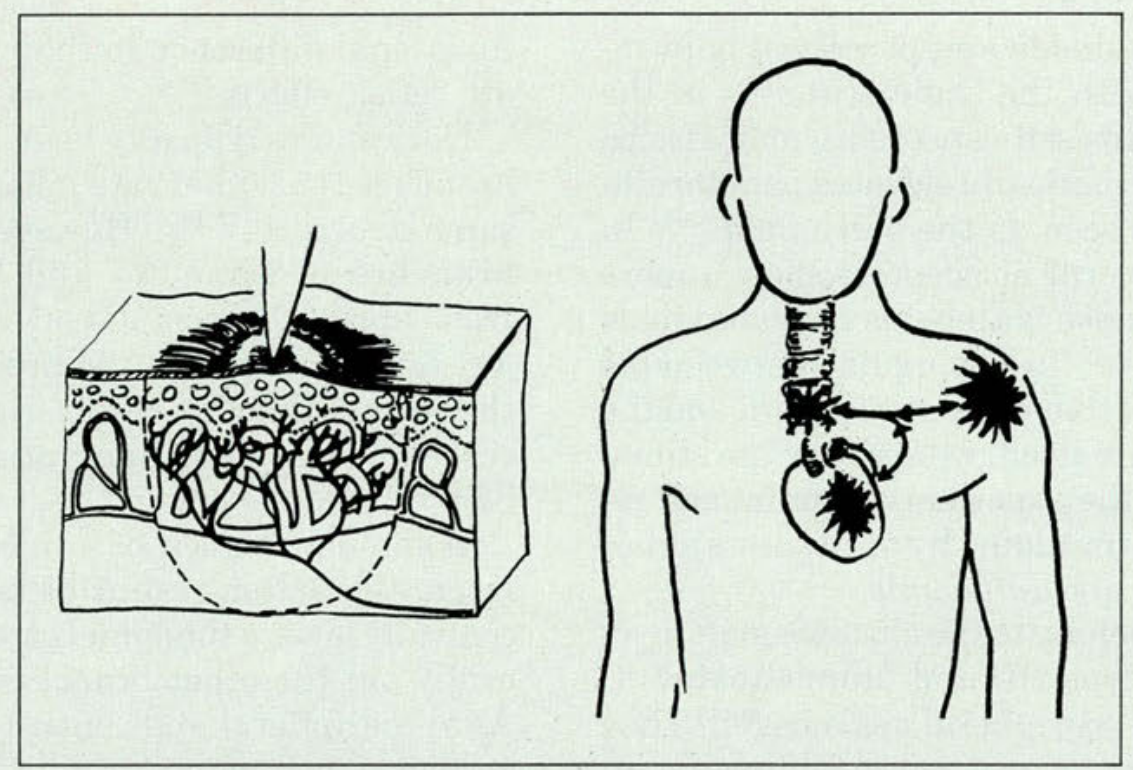

Figure 2. Peripheral branching of the nociceptor and its relation to the axon reflex (left) and convergence of inputs from diverse sources such as heart and shoulder (right).

Events that were previously benign, such as light pressure, can activate nociceptors following tissue insult, and will be interpreted as painful. In theory, this should be true at all terminals of the nociceptor. Thus, through axon reflexes, a positive feedback loop is established wherein nociception reinforces itself wherever it induces inflammation.

In addition to the axon reflex, there are two types of nociceptive reflexes involving the central nervous system. These are the nocifensive musculoskeletal reflex and the nociautonomic reflex. Both are based on connections the nociceptor makes in the spinal cord and brainstem. Peripheral nociceptor axons travel with both somatic and visceral nerves. However, all nociceptors, whichever route they take, have their cell bodies in the dorsal root ganglia or the cranial nerve ganglia along with other somatic and visceral sensory neurons. ${ }^{36,40-42,53}$ From the sensory ganglia, the nociceptors send axons into the spinal cord or brainstem, where they synapse. Many nociceptors terminate within the spinal segment of entry, but others may travel several spinal segments cephalad or caudad in Lissauer's tract before finally synapsing in the dorsal horn (Fig 3, top). ${ }^{40,41,53}$

Most nociceptors synapse in Rexed's lami- nae I and II or on dendrites of interneurons from lamina V (Fig 3, bottom). Some of the second-order nociresponsive neurons in laminae $I$ and $V$ send their axons cephalad in the spinothalamic and spinocervicothalamic tracts to the brainstem and thalamus, where their information serves conscious awareness and stimulates the affective content of pain..$^{36,40,41,53}$ Other lamina I and V neurons, and most of those in lamina II (substantia gelatinosa) remain as interneurons in the spin al cord, modulating the action of each other or serving in spinal noxious reflexes. These interneurons may act primarily within their spinal segment of origin or, like the nociceptors, project up to five segments cephalad or caudad. ${ }^{40,41,53}$

Some spinal interneurons, and even some of the peripheral nociceptors' afferents, project to the preganglionic neurons of the intermediolateral column to produce autonomic arousal $1,24,25,33,34,49,54$ (Fig 3, bottom). Others project to the motor neurons of the ventral (anterior) horn, driving musculoskeletal reflexes. ${ }^{36,40,41,53}$ (Fig 3 , bottom).

Individual dorsal horn neurons (laminae I through V), often respond to noxious stimulation of both somatic and visceral struc- 


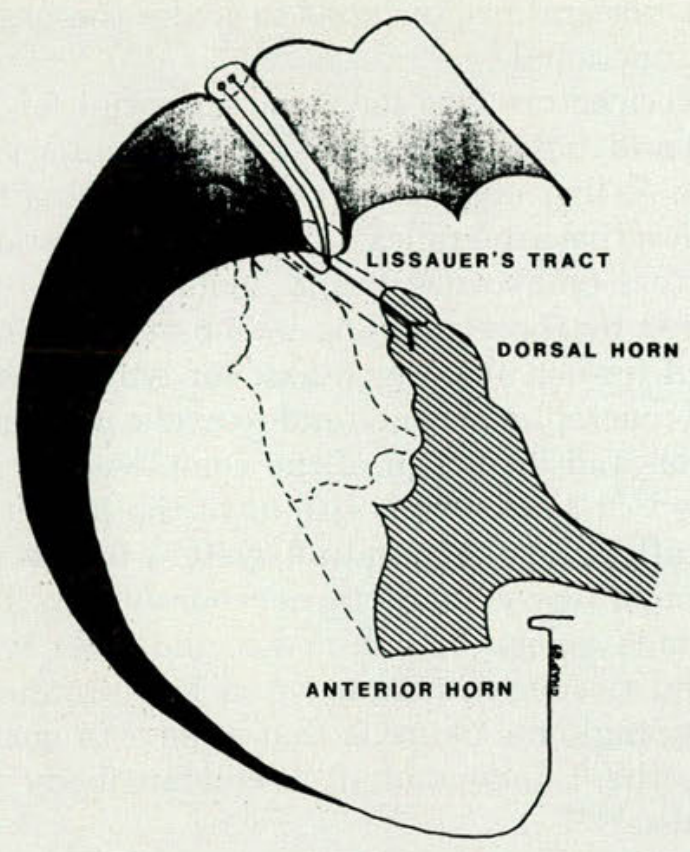

tures. ${ }^{40,41,55,56}$ This multiorgan responsiveness may stem from the peripheral bifurcation of nociceptor axons as aforenoted. However, there is also convergence of separate peripheral nociceptors from somatic and visceral structures like skin, skeletal muscle, and heart onto the same spinal neurons. ${ }^{41,55,56}$ This convergence is seen in neurons projecting cephalad to serve the sensation of pain, ${ }^{55,56}$ and is thought to be responsible for referred pain. ${ }^{35,36,55,56}$ Similar convergence is seen in nociresponsive spinal interneurons of laminae I through V. ${ }^{55}$

By accessing the pool of spinal interneurons, nociceptors are ensured diverging responses, both somatic and, via the autonomic nervous system, visceral (Fig 4). This combination of convergence from various noxious sources and divergence of outputs from nociresponsive spinal interneurons is probably the source of somatosomatic, somatovisceral, viscerosomatic, and viscerovisceral reflexes by which noxious stimulation produces distant and divergent responses. , $^{2,6}$ Noxious spinal reflexes are typically strongest in organs and muscles innervated by the same spinal segment (dermatome, myotome, sclerotome, or "viscerotome"), an association known as "local sign." However, noxious reflexes may spread to neighboring spinal segments, depending on the longitudinal projection of nociceptive axon terminals and spinal dorsal horn interneurons, as discussed earlier.

The musculoskeletal reflexes triggered by nociceptors are termed "nocifensive reflexes." 43 The classic demonstration of such a reflex is the flexion reflex seen primarily in the hindlimbs and, to a lesser extent, in the forelimbs of quadripeds. ${ }^{43}$ This reflex can be produced by noxious stimulation of skin, muscles, tendons, or periosteum of the affected limb. Following a delay sufficient for the slow-conduct-

Figure 3. Relationship between nociceptors and the spinal cord. Top: Nocioceptors terminate both in the spinal segment of entry and neighboring segments. Bottom: Nocioceptive neurons within the spinal cord distribute to the higher central nervous system, ventral motor neurons (skeletal muscles), and autonomic neurons. 
ing nociceptors plus synaptic processing in several spinal neurons, the limb flexor motor neurons and muscles are strongly activated and the antagonist extensor muscles are strongly inhibited, flexing the leg.

Although the flexion reflex is often considered the prototypical nocifensive reflex, in most cases, noxious stimuli do not drive only flexor muscles. For instance, noxious stimulation of the inner surface of the thigh typically produces extension and abduction of that limb. ${ }^{57}$ Again, noxious stimulation of an extensor muscle or its overlying skin generally produces activation of that muscle and extension of the affected limb. ${ }^{58}$ If noxious stimulation of a hindlimb is continued at a site that originally elicits flexion, stepping (alternation of flexors and extensors) may ensue. ${ }^{43}$ Finally, noxious stimulation of an intra-abdominal structure typically produces a guarding response, or tightening of the overlying abdominal muscles. ${ }^{40}$

Each of these nocifensive reflexes has in common the attempt to minimize the noxious stimulation, whether from a somatic or visceral source, utilizing connections within the spinal cord. That such reflexes can be modulated by the higher nervous system is without doubt, although they often occur in the absence of any perception of pain. ${ }^{57-61}$

The other spinal nociceptive reflex involves the autonomic nervous system. As in the nocifensive reflex, stimulation may be initiated from either somatic or visceral structures. Because the spinal machinery is common to both, ${ }^{55}$ noxious stimulation of somatic structures produces autonomic responses in both somatic and visceral structures, as does visceral noxious stimulation.

Most noxious stimuli evoke sympathetic responses. These responses may be segmental or more widely dispersed. A dispersed nociautonomic reflex might involve widespread vasoconstriction in skin and viscera, vasodilation in skeletal muscles, increased heart rate and blood pressure, and decreased gastric motility. ${ }^{62}$ Localized segmental autonomic activation is seen in other cases involving a single viscus and specific muscles, as noted earlier.
Anything that prolongs the sympathetic drive to a visceral organ tends to make the organ dysfunctional. ${ }^{5}$

Nociceptors also have the potential for direct and indirect influence on the immune system. As discussed earlier in the context of the nociceptive axon reflex, the peptide neurotransmitters (substance $\mathrm{P}$ and somatostatin) released by these neurons in somatic and visceral tissues are chemotaxic for lymphocytes and macrophages and tend to evoke degranulation and initiation of the complement cascade. ${ }^{11,52}$ Nociceptors also have the potential for affecting the immune system indirectly through the sympathetic nervous system. The thymus, spleen, lymph nodes, and other lymphoid tissues are innervated by autonomic postganglionic neurons that appear to modulate the T-independent B-cell antibody response. ${ }^{63-66}$

Immune cells also have surface beta- 2 receptors, which bind serum catecholamines. ${ }^{61-71}$ These receptors decrease macrophage phagocytosis and release of lysosomal enzymes, ${ }^{67,69}$ polymorphonuclear release of hydrolytic enzymes, ${ }^{67,70}$ and T-dependent antibody formation and antibody-mediated killer-cell cytotoxicity. ${ }^{67} \mathrm{~A}$ massive acute or chronic activation of the sympathetic nervous system, as by nociceptors, could therefore decrease the ability of the immune system to respond to a challenge. Such immune suppression is consistent with the reported health consequences of stress $^{72}$ and somatic dysfunction. ${ }^{1-8}$

Thus, nociceptors are virtually ubiquitous in the body, terminating throughout the connective tissues of all somatic and visceral structures. Through peripheral and spinal convergence and spinal divergence, nociceptors are able to generate autonomic and visceral responses to somatic noxious stimulation and vice versa. They also produce musculoskeletal responses that characteristically are aimed at decreasing the noxious stimulus reflexively. Finally, they can have significant effects on the immune system. All of these responses to noxious stimuli can occur with or without the sensation of pain because they are based on intrinsic spinal mechanisms. 


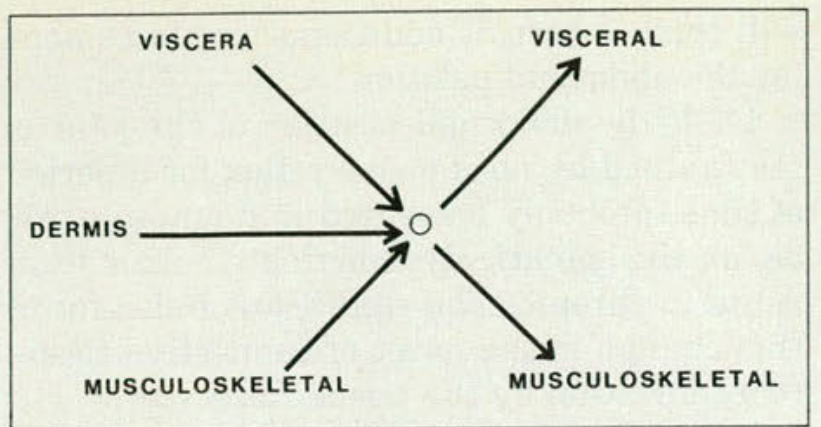

Figure 4. Convergence and divergence of nociceptive inputs resulting in somatosomatic, somatovisceral, viscerosomatic, and viscerovisceral reflexes.

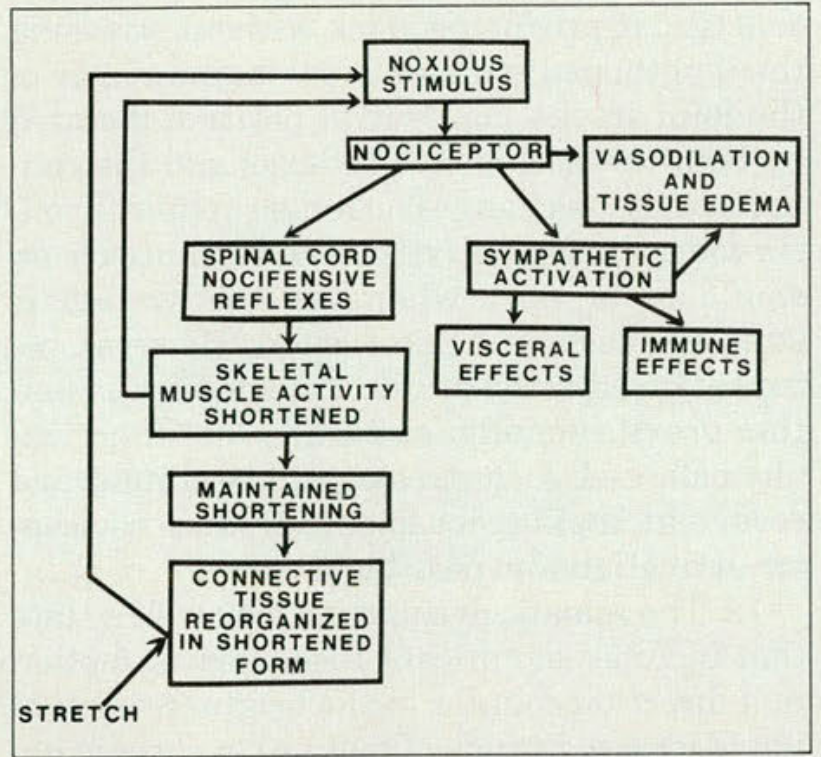

Figure 5. Model of nociceptive origin and maintenance of the somatic dysfunction.

\section{The model}

As discussed earlier, the somatic dysfunction is not a simple, localized musculoskeletal disorder. Rather, it ties local musculoskeletal restrictions to a variety of other phenomena, including pain, spread of restriction, autonomic arousal, visceral dysfunction, and disease and, by implication, decreases in the effectiveness of the immune system. Logically, if a single element can be found common to all of these phenomena, it would most likely have a crucial role in generation or maintenance (or both) of the somatic dysfunction. As we have just seen, the nociceptor is just such a common thread in the fabric of the somatic dysfunction.

The following model examines in a stepwise fashion how the nociceptor might create the rich fabric of the somatic dysfunction (Fig 5):

1. Minor trauma activates nociceptors in a muscle, probably not involving the whole muscle. Note that any disease or trauma in any somatic or visceral structure will also produce nociceptor activation.

2. Nociceptor activation sends impulses to other axon branches of the same nociceptor and into the spinal cord.

3. Impulses in the axon branches release peptide transmitters producing vasodilation, extravasation of fluid, and attraction of immune cells in and near the site of trauma. The immune cells then release other chemicals, reinforcing local vasodilation and extravasation and lowering the local threshold for nociception. Because nociceptor branches involve the initiating organ and other organs at a distance, the latter may also show the axon reflex effects. Thus, for instance, skeletal muscle and heart may be affected simultaneously.

4. Impulses entering the spinal cord synaptically stimulate spinal neurons. These spinal neurons can send impulses into the higher central nervous system for the appreciation of pain, or into the spinal intermediolateral system to stimulate the preganglionic autonomic neurons or, finally, into the spinal skeletal muscle motor pool, producing nocifensive reflexes.

5 . The pain, if perceived, may be poorly localized owing to the convergence of multiple sources onto the same spinal neurons and to the divergence of signals along neighboring segments of the spinal cord. Nonetheless, any pain and most reflex effects will be maximal in the segment of origin.

6. Most nociautonomic reflexes involve the sympathetic nervous system, with responses as diverse as cardiopressor, vasopressor, or vasodilator effects; gastrointestinal stasis; or bronchodilation. The specific response will be based on the sympathetic effect in the segmentally targeted organ. Maintenance of sympathetic drive tends to be detrimental to the normal 
function of the organ(s) involved. Immune function will also be diminished.

7. Nociceptive reflexes involve both specific segmental responses and often multisegmental attempts to minimize the noxious input by removing stress from the affected nociceptors. In some cases, the injured muscle will be shortened by action of its synergists or of those fibers within the muscle that are not traumatized. In other cases, overlying muscles will contract to guard the underlying damaged structure. In general, the final determinant of muscle contraction in a nocifensive reflex is whatever will minimize the noxious drive at the spinal level.

8. Axon reflex and sympathetic vasodilation effects engorge the affected muscles, producing direct mechanical restriction of motion. This occurs whether the muscles were the original source of injury or were involved secondarily, as in a viscerosomatic reflex. Tissue engorgement also stimulates local nociceptors, as do the tissue injury chemicals like serotonin, histamine, bradykinin, and potassium chloride.

9. Now, any attempt to restretch the affected muscles to their normal (nonstretched) position will restress the original nociceptors and trigger activity in any others with lowered thresholds. This positive feedback effect reinforces the guarding nocifensive reflexes. Keep in mind that the position best minimizing nociception in the case of nocifensive reflex is not likely to be at the maximally shortened position for a muscle around a joint. This is true primarily because maintenance of such an extreme will inevitably increase the stress on other structures in the body, including both the antagonist muscles and any muscles needed to stabilize the severely out-of-balance body. Thus, it is much more likely that titration of a noxious input will produce a new musculoskeletal relationship that is no longer in neutral position, but not at the maximum range.

10. Continuing contraction of those muscles actively maintaining the shortened position will begin to produce products of fatigue that also activate the nociceptors. ${ }^{40}$ This process will tend to recruit additional reinforcement for the abnormal position.

11. If the abnormal position of the joint is maintained by nocifensive reflex for a period of time (probably measured in hours to a few days), the somatic dysfunction changes from acute to chronic. The significant indicator of this change is the onset of connective tissue reorganization by the tissue fibrocytes.

In the shortened muscle, the connective tissue fibers will become more random in orientation and, therefore, less able to take stress along the ordinary lines of force. In the lengthened muscles, creep will elongate the connective tissue, producing slack without stressing the lengthened muscles. Now maintenance of the joint in the nonneutral position dictated by both the nocifensive reflexes and the connective tissue changes no longer requires continuous muscle activity. Active contraction would occur only whenever the system is stressed, reactivating nociceptors. However, because the adjusted position at the joint is neither gravitationally, posturally, nor functionally balanced, such stresses will be chronic and recurrent, making it easier to produce nociceptor activation and possible perception of pain.

12. The somatic dysfunction is now in a state that includes significant resistance to motion in a direction counter to the original shortening (decreased range of motion), a chronic nociceptor activation that may or may not be perceived as pain, and continuous autonomic activation, producing visceral and immune deficits.

\section{Discussion}

The model proposed here is supported by an extensive body of data, as discussed. It focuses on the nociceptor as the primary agent in initiation and maintenance of the somatic dysfunction. It is not a simple model, just as the effects it attempts to explain are not simple. Although essentially a neurologic model, it includes changes in connective tissue and local circulation as integral parts of the dysfunction. By including musculoskeletal restriction and autonomic, visceral, and immunologic deficits as consequences of its mechanism of action, 
the proposed model appears to explain satisfactorily all the major features of the somatic dysfunction.

The model, as delineated, does account for the development of a quasi-stable musculoskeletal restriction as connective tissues reorganize along dysfunctional lines. It also demonstrates a strong anatomic and physiologic connection between the musculoskeletal and visceral and autonomic systems. However, it cannot readily account for the chronic autonomic and immune effects seen in the somatic dysfunction because these effects are proposed to be secondary to nociceptor activity, and nociceptors, like other sensory receptors, are subject to adaptation..$^{36,40,49}$ Further, in accord with this model, the object of the reflexes is to keep the affected tissues in their shortened state, effectively silencing the nociceptors.

However, it is likely that the body would more or less continually restress these abnormal tissues in the pursuit of balance and in normal activity, as suggested earlier. With the lower sensory thresholds in these tissues secondary to tissue edema, effects of local inflammatory products, and increased sympathetic tone, one might expect frequent and prolonged (although not necessarily continuous) nociceptor activation. In fact, in patients with somatic dysfunctions, pain commonly is a more or less chronic accompaniment and may indeed be the presenting complaint.

Finally, as suggested by Patterson, ${ }^{73}$ chronic, and even short-term, alterations in sensory input to the central nervous system can result in enduring changes in central processing. These processes of classic conditioning and fixation are particularly applicable to stimuli of the sort represented by the nociceptor and outputs such as the vegetative responses of the autonomic nervous system.

Most of the stresses and minor traumas of everyday life do not result in the development of somatic dysfunction. Why this is true is a significant question in light of the reflex nature of events proposed in the current model of somatic dysfunction. First, as discussed by Patterson, ${ }^{73}$ reflexes, while "wired in" to an extent, are subject to multiple other inputs that modulate their effects. Further, even supposing the nociceptive reflex sequence has proceeded apace, activities of daily living and conscious and unconscious attempts to revert to more gravitationally neutral positions might well override a local guarding reflex, stretching tissues back out before they become reorganized, breaking the cycle.

The spontaneous resolution of a potential somatic dysfunction by stretching in turn suggests the manner in which manipulative treatment achieves its reduction of somatic dysfunction. Although there are many different techniques used by osteopathic physicians to relieve somatic dysfunction, they all appear to actively stretch the connective tissues in joint capsules, tendons, muscles, and ligaments in the area of restricted motion. Any such stretching should increase nociceptive drive and thereby strengthen the somatic dysfunction. Therefore, to be successful, the various manipulative treatments must be decreasing or overriding such a nociceptive drive, probably through whatever technique is used to prepare the tissue prior to stretching. It is this preparation that appears to set the different techniques apart.

For instance, in indirect "muscle energy," the skeletal muscles in the shortened area are initially stretched to the maximum extent allowed by the somatic dysfunction. With the tissues held in this position, the patient is instructed to contract the affected muscles voluntarily. This isometric activation of the muscle will stretch the internal connective tissues. Voluntary activation of motor neurons to the same muscles also blocks transmission in spinal nociceptive pathways. ${ }^{11,40}$ Immediately following the isometric phase, passive extrinsic stretch is imposed, further lengthening the tissues toward the normal "easy neutral" position.

In counterstrain, in contrast, the already shortened and restricted tissues are initially further shortened. Maximal shortening removes all internal stresses in the shortened tissues, totally deactivating the nociceptors. By holding the tissues in this position for at least 90 seconds, local circulation will improve due 
to release from the chronic sympathetic stimulation. Local inflammation will decrease as the noxious chemicals are carried away, as will tissue edema. If the tissues are then slowly, but passively, stretched, as emphasized by practitioners of this technique, the connective tissues will be allowed to elongate and creep, absorbing the forces involved and preventing distribution of these forces to the nociceptor endings.

Myofascial techniques also use an initial shortening of the restricted connective tissues and muscles. This shortening is followed by a gradual stretch of these tissues in all directions natural to the affected portion of the body. Again, the stretching is done slowly, decreasing the likelihood of stressing the nociceptors.

Finally, in the case of the high-velocity-lowamplitude technique so widely used by osteopathic physicians, the restricted tissue is stretched carefully to its abnormal limit. This careful positioning avoids further activation of the nociceptors in the affected tissues. The physician then quickly induces a small additional stretch on the affected tissues. Particularly in the case of the joints and their capsules, this additional stretching will tend to force a swift reorganization of the randomized, restricted connective tissues, possibly by breaking those fibers that were oriented other than along the normal lines of force at the joint. With high speed, the relatively slow nocifensive reflexes cannot be brought into play to block the movement. By using only a lowamplitude, carefully vectored force, the operator minimizes tissue damage.

In spite of these techniques' attempts to reduce the consequences of stressing the previously restricted tissues during stretch, it is obvious that some stress, damage, and nociceptor activation will occur during and following manipulative treatment. In many cases, this nociceptor activation will not be of sufficient magnitude to override the newly recovered freedom of motion and balance against gravity. However, as is widely recognized by those using manipulative treatment, the treatment will sometimes induce reactivation of the no- ciceptor-reflex-inflammation sequence hypothesized here to underlie the somatic dysfunction.

To reduce the probability of reinstatement of the somatic dysfunction after manipulative treatment, many osteopathic physicians prescribe a nonsteroidal anti-inflammatory drug (NSAID) after treatment. In the context of the current model, this is exactly the right preventive treatment. The NSAIDs block responsiveness of peripheral nociceptors to noxious stimuli directly. They also block prostaglandin production, thereby decreasing local inflammation with its effects. It might be asked why NSAIDs are often not sufficient in themselves to block somatic dysfunctions. Quite possibly, NSAIDs can block development of somatic dysfunctions if taken directly following the initial tissue insult before tissue reorganization begins. However, if the connective tissues have been remodeled, blockade of nociceptors by itself probably will not be sufficient to remove an extant somatic dysfunction. Both the reorganized, shortened connective tissue and the remaining internal organ dysfunctions would tend to act as ballast against the normalization of tissues, even in the absence of nociceptive reflexes.

As suggested earlier, a number of models have previously proposed a connection between the functional restrictions in musculoskeletal motion and pain. ${ }^{35-38}$ Several models, such as that of Travell ${ }^{37}$ and Travell and Simons, ${ }^{38}$ have even recognized that such a relationship includes autonomic and visceral dysfunction, although these are viewed as epiphenomena, and certainly not as being central to the development or maintenance (or both) of disease. Again, Travell and Simons ${ }^{38}$ and Popelianskii and coworkers ${ }^{74}$ have proposed that there is a two-phase development of such musculoskeletal restrictions involving pain followed by connective-tissue reorganization. However, all such models have emphasized the conscious component of pain and its avoidance, whereas the current model suggests that the events leading to somatic dysfunction are purely reflexive. Pain in the current model is, in fact, an epiphenomenon that may be a sign of somatic dysfunction. It may even be what brings the pa- 
tient to the physician, but it is neither the cause of nor a necessary concomitant of the somatic dysfunction.

Few, if any, of the previous pain-related models of musculoskeletal restrictions have recognized the central role of reflexive autonomic arousal in development of the many concomitant dysfunctions, including immune system dysfunction. Also, because most models have concentrated on musculoskeletal dysfunctions themselves, few such models have recognized that the same nociceptive mechanisms can cause musculoskeletal consequences as a result of visceral disorders. The two-way street between somatic and visceral dysfunction is an essential feature of the osteopathic concept and cannot be ignored.

Finally, a few words should be said about validation of the current model. It is clear that a model this complex has a number of areas that can and should be examined empirically. First, because the assertion is that nociception is central to the onset and part of the mechanism maintaining the somatic dysfunction, examination of the clinical consequences of musculoskeletal stress with and without peripheral nociceptor blockade should be a fair test of the concept. Second, central blockade of nociception above the spinal level should have no appreciable effect on development or maintenance of somatic dysfunctions. Third, longitudinal examination of immune function before, during, and after development and manipulative elimination of somatic dysfunction should determine whether immune function is as closely related to somatic dysfunction as the current model suggests. Although clinical experience and some experiments ${ }^{1-4,6-8}$ tend to support the contention that somatic dysfunctions involve visceral as well as somatic consequences, further experimental support would be useful.

It should be kept in mind that the model proposed here remains hypothetical. It does appear to explain most of the phenomena of the somatic dysfunction as understood by osteopathic medicine, relying mostly on known properties of nociceptors, spinal cord reflexive organization, and connective-tissue properties.
The model, as stated earlier, is not simple, but does not require too many organizing principles or outright assumptions. However, until it is supported by more experimental data, whether derived clinically or in the laboratory, it remains simply one of several competing hypotheses.

The model described here has evolved from those that have been proposed before, particularly that of Korr. Although essentially neurologic, the current model recognizes clearly that changes in circulation and connective tissue develop directly from and tend to reinforce the nociceptive and other neural changes thought to underlie the somatic dysfunction. The principal point on which this model differs is the identification of the nociceptor as the sensory element that ties together involuntary muscle restrictions, autonomic arousal, and consequent circulatory and immunologic changes in the somatic dysfunction.

1. Still AT: The Philosophy and Mechanical Principles of Osteopathy. Kansas City, Mo, Hudson Kimberly Publishing Co, 1902, pp 18-21.

2. Burns L, Chandler LC, Rice RW: Pathogenesis of Visceral Disease Following Vertebral Lesions. Chicago, American Osteopathic Association, 1948, pp 31-33, 49-54.

3. Beal MC: Viscerosomatic reflexes: A review. JAOA 1985;85:786-801.

4. Burns L: Viscero-somatic and somato-visceral spinal reflexes. JAOA 1907;7:51-60.

5. Korr IM: Sustained sympathicotonia as a factor in disease, in Korr IM (ed): The Neurobiological Mechanisms in Manipulative Therapy. New York, Plenum Publishing Co, 1978, pp 229 268.

6. Beal MC, Morlock JW: Somatic dysfunction associated with pulmonary disease. JAOA 1984;84:179-183.

7. Beal MC, Kleibner GE: Somatic dysfunction as a predictor of coronary artery disease. JAOA 1985;85:302-307.

8. Burns L: Studies in the Osteopathic Sciences. Vol 1. Basic Principles. Los Angeles, The Occident Printery, 1907.

9. Zink JG: Respiration and circulatory care: The conceptual model. Osteopathic Ann 1977;5:108-112.

10. Goldman S, Newgent E, Ingram C: The model of respiratory and circulatory care. Osteopathic Ann 1983;11:443-449.

11. Awal EA: Interstitial myofibrosis: Hypothesis of the mechanism. Arch Phys Med 1973;54:440-453.

12. Hettinga DL: Normal joint structures and their reaction to injury I. J Orthop Sports Phys Ther 1979;1:16-22.

13. Hettinga DL: Normal joint structures and their reaction to injury II. J Orthop Sports Phys Ther 1979;1:83-88.

14. Michlke K, Schulze G, Eger W: Klinische und Experimentalle Untersuchungen Zum Fibrositis-syndrome. Z Rheumaforsch 1960;19:310-330. 
15. Frost HM: The Physiology of Cartilagenous, Fibrous, and Body Tissue. Springfield, Ill, Charles C Thomas Publisher, 1972.

16. Adams RD: Diseases of Muscle: A Study in Pathology, ed 3. Hagerstown, Md, Harper \& Row Publishers, Inc, 1975.

17. Fassbender HG: Pathology of Rheumatic Diseases. New York, Spinger-Verlag, 1975, pp 303-314.

18. Frymann VM: The core-link and the three diaphragms: A unit for respiratory function. Academy of Applied Osteopathy 1968 Year Book of Selected Osteopathic Papers. Fort Worth, Tex, Academy of Applied Osteopathy, pp 13-19.

19. Denslow JS: An analysis of the variability of spinal reflex thresholds. $J$ Neurophysiol 1944;7:207-215.

20. Denslow JS, Hassett CC: The central excitatory state associated with postural abnormalities. J Neurophysiol 1944;5:393402.

21. Denslow JS, Korr IM, Krems AD: Quantitative studies of chronic facilitation in human motoneuron pool. Am $J$ Physiol 1947;105:229-238.

22. Korr IM: The neural basis of the osteopathic lesion. JAOA 1947;191-198.

23. Korr IM: Proprioceptors and somatic dysfunction. JAOA 1975;638-650.

24. Korr IM, Wright HM, Thomas PE: Effects of experimental myofascial insults on cutaneous patterns of sympathetic activity in man. J Neural Transm 1962;23:330-355.

25. Korr IM, Wright HM, Chace JA: Cutaneous patterns of sympathetic activity in clinical abnormalities of the musculoskeletal system. J Neural Transm 1964;25:589-606.

26. Laporte Y, Lloyd DPC: Nature and significance of the reflex connections established by the large afferent fibers of muscular origin. Am J Physiol 1952;169:609-621.

27. Valbo AB: Afferent discharge from human muscle spindles in non-contracting muscles. Steady state impulse frequency as a function of joint angle. Acta Physiol Scand 1974;90:303-318.

28. Valbo AB, Hagbarth KE, Torebjork HE, et al: Somatosensory proprioceptive and sympathetic activity in human peripheral nerves. Physiol Rev 1979;59:919-957.

29. Matthews PBC: Proprioceptors and the regulation of movement, in Towe AL, Luscher ES (eds): Handbook of Behavioral Neurobiology, Vol 5: Motor Coordination. New York, Plenum Press, 1981, pp 93-107.

30. Baldissera F, Hultborn $\mathrm{H}$, Illert M: Integration in spinal neural systems, in Brooks VB (ed): Handbook of Physiology, Sect 1, The Nervous System, Vol II, Part 1. Bethesda, Md, American Physiological Society, 1981, pp 509-595.

31. Matthews PC: Muscle spindles: Their messages and their fusimotor supply, in Brooks VB (ed): Handbook of Physiology, Sect 1, The Nervous System, Vol II, Part 1. Bethesda, Md, American Physiological Society, 1981

32. Sato A, Schmidt RF: Somatosympathetic reflexes: Afferent fibers, central pathways, discharge characteristics. Physiol Rev 1973;53:916-947.

33. Sato A, Sato Y, Schmidt RF: The effects of somatic afferent activity on the heart rate, in Brooks CM, Koizumi K, Sato A (eds): Integrative Functions of the Autonomic Nervous System. Tokyo, Japan, University of Tokyo Press/Elsevier, 1979.

34. Buzzell KA: The potential disruptive influence of somatic input, in The Physiologic Basis of Osteopathic Medicine. New York, Postgraduate Institute of Osteopathic Medicine and Surgery, 1970, pp 39-51.

35. Ruch TC: Visceral sensation and referred pain, in Fulton
JF (ed): Howell's Textbook of Physiology, ed 5. Philadelphia, WB Saunders Co, 1946, pp 385-401.

36. Ruch TC: Pathophysiology of pain, in Ruch T, Patton HD (eds): Physiology and Biophysics: The Brain and Neural Function, ed 2. Philadelphia, WB Saunders Co, 1979, pp 272-324.

37. Travell J: Myofascial tender points: Clinical view, in Bonica JJ, Albe-Fessard D (eds): Advances in Pain Research and Therapy, Vol I. New York, Raven Press, 1976, pp 919-926.

38. Travell JG, Simons DG: Myofascial Pain and Dysfunction: The Trigger Point Manual. Baltimore, Williams \& Wilkins Co, 1982.

39. Sherrington CS: The Integrative Action of the Nervous System. New York, Scribners, 1906.

40. Mountcastle VB (ed): Medical Physiology, Vol 1. St Louis, CV Mosby Co, 1980, pp 391-427.

41. Dubner R, Bennett GJ: Spinal and trigeminal mechanisms of nociception. Ann Rev Neurosci 1983;6:381-418.

42. Iggo A: Activation of cutaneous nociceptors and their actions on dorsal horn neurons. Adv Neurol 1974;4:1-9.

43. Sherrington CS: Flexion-reflex of the limb, crossed extension reflex, and reflex stepping and standing. J Physiol (London) $1910 ; 40: 28-121$

44. Feindel WH, Weddell G, Sinclair DC: Pain sensibility in deep somatic structures. J Neurol Neurosurg Psychiatry 1948;11:113-117.

45. Stacey MJ: Free nerve endings in skeletal muscle of the cat. $J$ Anat 1961;105:231-254.

46. Stilwell DL Jr: Regional variations in the innervation of deep fascia and aponeuroses. Anat Rec 1957;127:635-653.

47. Stilwell DL Jr: The innervation of tendons and aponeuroses. Am $J$ Anat 1957;100:289-317.

48. Landau W, Bishop GH: Pain from dermal, periosteal and fascia endings from inflammation: Electrophysiological study employing differential nerve blocks. Arch Neurol Psychiatry (Chicago) $1953 ; 490-504$.

49. Geldard FA: The Human Senses, ed 2. New York, John Wiley \& Sons, 1974

50. Pierau Fr-K, Fellmer G, Taylor DCM: Somato-visceral convergence in cat dorsal root ganglion neurons demonstrated by double-labelling with fluorescent tracers. Brain Res 1984;321:6370 .

51. Alles A, Dom RM: Peripheral sensory nerve fibers that dichotomize to supply the brachium and pericardium in the rat: A possible morphological explanation for referred cardiac pain? Brain Res 1985;342:382-385.

52. Johnson AR, Erdos EG: Release of histamine from mast cells by vasoactive peptides. Proc Exp Biol Med 1978;142:12521256.

53. Kerr FWL: Neuroanatomical substrates of nociception in the spinal cord. Pain 1975;1:325-356.

54. Morgan C, deGroat WC, Nadelhaft I: Identification of visceral afferents to the sacral cord of the cat using horseradish peroxidase. Neurosci Abstr 1978;4:23.

55. Craig AD, Kniffki A: Spinothalamic lumbosacral lamina I cells responsive to skin and muscle stimulation in the cat. $J$ Physiol 1985;365:197-221.

56. Foreman RD, Blair RW, Weber RN: Viscerosomatic convergence onto t2-t4 spinoreticular, spinoreticular-spinothalamic and spinothalamic tract neurons in the cat. Exp Neurol 1984;85:597-619.

57. Megirian D: Bilateral faciliatory and inhibitory skin areas of spinal motoneurons of the cat. J Neurophysiol 1962;25:127-137. 
58. Hagbarth K-E: Excitatory and inhibitory skin areas for flexor and extensor mononeurons. Acta Physiol Scand 1952;26(suppl 94)a:58.

59. Hagbarth KE, Finer BL: The plasticity of human withdrawal reflexes to noxious skin stimuli in lower limbs. Prog Brain Res $1963 ; 19: 65-81$.

60. Kugelbert E, Hagbarth KE: Spinal mechanisms of the abdominal and erector spinae skin reflexes. Brain 1958;81:390-404.

61. Shahani BT, Young RR: Human flexor reflexes. $J$ Neurol Neurosurg Psychiatry 1971;34:616-627.

62. Aihara Y, Nakamura H, Sato A, et al: Neural control of gastric motility with special reference to cutaneogastric reflexes, in Brooks C, Sato A (eds): Integrative Functions of the Autonomic Nervous System. Tokyo, University of Japan Press/ Elsevier, 1979, pp 38-49.

63. Bulloch K, Morre RY: Innervation of the thymus gland by the brain and spinal cord in mouse and rat. Am J Anat $1981 ; 162: 157-166$.

64. Bullock K: Neuroanatomy of lymphoid tissue: A review, in Guillemin R, Cohn M, Melnechuk T (eds): Neural Modulation of Immunity. New York, Raven Press, 1985, pp 111-141.

65. Miles K, Quintans J, Chelmicka-Schorr E, et al: The sympathetic nervous system modulates antibody response to thymusindependent antigens. $J$ Neuroimmunol 1981;1:101-105.

66. Williams JM, Peterson RG, Shea PA, et al: Sympathetic innervation of murine thymus and spleen: Evidence for a func- tional link between the nervous and immune systems. Brain Res Bull1981;6:83-94.

67. Ahlqvist $\mathrm{J}$ : Hormonal influences in immunological and related phenomena, in Ader R (ed): Psychoneuroimmunology. New York, Academic Press, 1981, pp 355-403.

68. Bourne HR, Lichtenstein LM, Melmon KL, et al: Moderation of inflammation and immunity by cyclic AMP. Science 1974;184:19-28.

69. Hall NR, Goldstein AL: Neurotransmitters and the immune system, in Ader R (ed): Psychoneuroimmunology.New York, Academic Press, 1981, pp 521-543.

70. Motulsky HJ, Insel PA: Adrenergic receptors in man. NEngl $J$ Med 1982;307:18-29.

71. Pochet R, Deleperse G, Gauseet PW, et al: Distribution of beta-adrenergic receptors on human lymphocyte subpopulations. Clin Exp Immunol 1979;38:578-584.

72. Selye H: Stress and disease. Science 1955;122:625-631.

73. Patterson MM, Steinmetz JE: Long-lasting alterations of spinal reflexes: A potential basis for somatic dysfunction. Manual Med 1986;2:38-45.

74. Popelianskii II, Zaslavskii ES, Veselovskii VP: (Mediosocial significance, etiology, pathogenesis, and diagnosis of nonarticular disease of soft tissues of the limbs and back.) (Russian) Vopr Revm 1976;3:38-43, cited by Travell JG, Simons DG: Myofascial Pain and Dysfunction: The Trigger Point Manual. Baltimore, Williams \& Wilkins Co, 1982. 